\title{
Effect of Symptoms of Adult Attention Deficit Hyperactivity Disorder on Symptoms of Post Traumatic Stress Disorder in Korean Conscripts
}

\author{
Dong-Yun Lee ${ }^{1}$, Cheol-Soon Lee ${ }^{2}$, Chul-Soo Park², Bong-Jo Kim², \\ Bo-Seok Cha' ${ }^{2}$, So-Jin Lee ${ }^{2}$ and Soo Young Bhang ${ }^{3}$ \\ ${ }^{1}$ Medical Unit of $9^{\text {th }}$ Division, Korea Army, Goyang, Korea \\ ${ }^{2}$ Department of Psychiatry, School of Medicine, Gyeongsang National University, Jinju, Korea \\ ${ }^{3}$ Department of Psychiatry, College of Medicine, University of Ulsan, Ulsan, Korea
}

Objective This study is conducted to investigate the effect of symptoms of Attention Deficit and Hyperactivity Disorder (ADHD) on symptoms of Posttraumatic Stress Disorder (PTSD) among 224 conscripts during 5 weeks of military basic training.

Methods Total number of subject is 224 conscripts. We evaluated past and present symptoms of ADHD with Korean-Wender Utah rating scale (K-WURS) and Korean adult attention -deficit/hyperactivity disorder scale (K-AADHDS) and stress and symptoms of PTSD with Brief Encounter Psychosocial Instrument-K (BEPSI-K), the Korean version of the Impact of Event Scale-Revised (IES-R-K) on 1 week and 5 weeks later of basic military training. Pearson correlation analysis and multivariate logistic regression analysis were performed to evaluate risk factors of PTSD using SPSS program and Path analysis also was used to find relationship between past and present ADHD and PTSD simultaneously using AMOS program.

Results Present symptoms of ADHD (OR=1.145, CI=1.054-1.245, $\mathrm{p}=0.001)$ and Past symptoms of ADHD (OR=1.049, CI=1.005$1.095, \mathrm{p}=0.028)$ were significant risk factor of PTSD symptoms on 1st week of basic military training. The symptoms of PTSD on fist week was also significant risk factor of PTSD after 5weeks of basic military training $(\mathrm{OR}=1.073, \mathrm{CI}=1.020-1.129$, $\mathrm{p}=0.006)$. Using path analysis, we could found confirm these relations between past and present ADHD symptoms and symptoms of PTSD.

Conclusion The result suggests that past and present symptoms of ADHD are the risk factor of symptoms of PTSD on first week. And the symptoms of PTSD on first week are also risk factor of PTSD symptoms on last weeks in Korean conscripts. The symptoms of ADHD might make an important role in vulnerability of the symptoms of PTSD in Korean conscripts.

Psychiatry Investig 2012;9:154-160

Key Words Adult ADHD, PTSD.

\section{INTRODUCTION}

Post-Traumatic Stress Disorder (PTSD) is a psychiatric disorder in which symptoms such as re-experience, hyperarousal, and avoidance follow an experience of unpredicted traumatic stress. ${ }^{1}$ PTSD does not present identically for all who experience the same type of trauma because the development of the disorder is influenced by the individual's vulnerability factors. ${ }^{2}$

\footnotetext{
Received: September 22, 2011 Revised: February 8, 2012 Accepted: March 15, 2012 Available online: May 22, 2012

$\triangle$ Correspondence: Cheol-Soon Lee, MD, PhD

Department of Psychiatry, School of Medicine, Gyeongsang National University, 90 Chiram-dong, Jinju 660-702, Korea

Tel: +82-55-750-8872, Fax: +82-55-759-0003, E-mail: psy@gnu.ac.kr

(c) This is an Open Access article distributed under the terms of the Creative Commons Attribution Non-Commercial License (http://creativecommons.org/licenses/bync/3.0) which permits unrestricted non-commercial use, distribution, and reproduction in any medium, provided the original work is properly cited.
}

PTSD vulnerability factors include trauma inflicted during childhood, personality disorders, genetic vulnerability to psychiatric disorders, and recent drastic change in the living environment, among others. ${ }^{3}$ Those who have these susceptibilities may develop PTSD after a relatively small mental trauma. ${ }^{4}$

Attention-Deficit/Hyperactivity Disorder (ADHD) is characterized by lack of attention, impulsiveness, and hyperactivity ${ }^{5}$ and is a developmental disorder that affects $50 \%$ of child and adolescent psychiatric outpatients. ADHD is a common neurodevelopmental disorder associated with family and social problems, behavioral and educational difficulties, and cognitive dysfunction. ${ }^{6}$ In the past, ADHD was considered a childhood disorder because the symptoms were thought to improve as the child develops. ${ }^{7}$ However, $50-65 \%$ of ADHD patients continue to satisfy the diagnostic criteria after they reach adulthood. Adults with ADHD have a prevalence ratio 
of $3-5 \%,{ }^{8}$ and studies have consequently concluded that ADHD symptoms need to be treated well into adulthood. ${ }^{9}$ ADHD that emerges during childhood may be accompanied by antisocial personality disorders, anxiety disorders, and depressive disorders, ${ }^{9}$ and a number of studies report that mood and depressive disorders are comorbid. ${ }^{10,11}$ Among depressive disorders, the symptoms of PTSD can appear similar to those of ADHD, necessitating differential diagnosis. ${ }^{12,13}$ Also, the symptoms of ADHD are often perceived as personality or character traits of the individual and are thus overlooked. ${ }^{14}$ Because of comorbidities and other factors, the symptoms of ADHD in adults are easily overlooked, difficult to evaluate, and often ignored. ${ }^{14}$

In South Korea, most soldiers are in late adolescence when they begin military service. Late adolescence is a developmental phase involving the transition to adulthood, and late adolescents do not yet have a fully developed or effective stress response system. ${ }^{15}$ Enlisting in the military entails many environmental changes and continuous tension, and many of these youths experience considerable psychological pressures in military life. ${ }^{16}$ Serious maladjustment to military life can engender many societal problems. ${ }^{17}$ Military service begins with basic military training, which introduces stressors such as the unfamiliar environment of the training center and the individual's new role as a soldier. ${ }^{18}$ It has been reported that stress is most severe during the basic military training period and in situations of compulsory military service such as in Israel. ${ }^{19}$ Individuals with ADHD symptoms have difficulties adjusting to new environments as well as low self-efficacy. ${ }^{20}$ Considering these factors, it can be assumed that individuals with ADHD symptoms may have a hard time adjusting to the military environment, and the variety of environmental stressors could induce the development of PTSD. However, the literature regarding adult ADHD in Korea is meager at present. Past studies on adjustment to military life have focused primarily on environmental factors, and there is still a strong need for research on the psychopathology of this adjustment. Moreover, most studies on ADHD and PTSD have been retrospective or focused on children. This study aims to comprehend the effects of past and present symptoms of adult ADHD on the stress and symptoms of PTSD. The subjects of this study were new recruits participating in the 5-week long basic military training in South Korea.

\section{METHODS}

\section{Subject and procedure}

This study was conducted on new recruits entering an army unit in 2011 after the physical examination post-conscription confirmed the absence of marked medical diseases. A survey was conducted as part of the mental and psychological examination, which accompanied the physical examination the new recruits underwent before entering the training camp. The researcher collected the questionnaires immediately after the subjects finished their training. A psychiatrist visited the training camp in person on the first day after admittance, explained the purpose of the examination, and received consent. For the first survey, a demographical survey, the Korean version of the adult attention-deficit/hyperactivity disorder scale (K-AADHDS), the Korean-Wender Utah Rating Scale (K-WURS), the Korean version of the Impact of Event ScaleRevised in Korean (IES-R-K), and the Korean version of the Brief Encounter Psychological Instrument (BEPSI-K) were administered to 258 respondents before training. For the second survey, the Korean version of the Impact of Event ScaleRevised (IES-R-K) and the Brief Encounter Psychological Instrument-K (BEPSI-K) were given to 271 respondents in the fifth week after training was complete. Of the survey participants, only the 224 respondents who answered both the first and second surveys were included as study subjects. This study was approved by the Clinical Medical Research Ethics Committee of the Korean Armed Forces Medical Command.

\section{Measure}

\section{Korean Adult Attention-Deficit/Hyperactivity Disorder Scale (K-AADHDS)}

The K-AADHDS was developed in 1995 by Murphy and Barkley to assess ADHD symptoms in adults, and it has been translated into Korean. This self-rating scale is constructed from $18 \mathrm{ADHD}$ symptoms listed in the DSM-IV and consists of 9 questions that measure lack of attention and 9 questions about hyperactivity and impulsiveness for a total of 18 questions. The scale evaluates present ADHD symptoms and assesses how often the symptoms have occurred over the preceding 6 months, with a 4-point scale ranging from 'almost never' to 'very often.' In Korea, the reliability and validity of this scale were verified in a study conducted on 553 college students. ${ }^{21}$

\section{Korean-Wender Utah Rating Scale (K-WURS)}

The K-WURS consists of 25 questions that aid in the diagnosis of ADHD in adults. Developed by Wender in 1993, it is a self-rating 5-point scale ranging from 0 (not at all) to 4 (very much so) with a minimum total of 0 points and a maximum total of 100 points. A total of more than 46 points indicates adult ADHD by the United States' standard. This scale has been used in many past studies that evaluated the symptoms of $\mathrm{ADHD}{ }^{22}$ 


\section{Impact of Event Scale-Revised (IES-R-K)}

This is a self-rating scale of trauma-related symptoms developed by Horwitz et al., ${ }^{23}$ and is now the most extensively used scale of its kind worldwide. ${ }^{24}$ However, the original IES cannot measure hyperarousal, which is one of the core characteristics of PTSD. Weiss and Marmar developed the revised IES in $1994^{25}$ to include hyperarousal. In the revised IES, the 15 questions of the original IES were expanded into 22 questions and were reconstructed to measure 8 intrusion symptoms, 8 avoidance symptoms, and 6 hyperarousal symptoms. The scoring system was also modified: the original IES evaluated the frequency of the symptoms during the preceding week using a 4-point scale (0-1-3-5), and the IES-R-K evaluates the severity of the symptoms during the preceding week using a 5-point scale (0-4). In Korea, the reliability and validity of the scale have been verified by a study conducted on 173 college students, with PTSD identified above $24 / 25$ points and considered questionable above $17 / 18$ points. ${ }^{26}$

\section{Brief Encounter Psychosocial Instrument-K (BEPSI-K)}

The BEPSI-K, developed in 1998 by Frank and Zyznaski, is an instrument that evaluates the negative effects of stress on health, based on the model of stress as a dynamic interaction. This test was translated to develop the Korean Version of the BEPSI-K measuring instrument. This test is composed of 5 questions, each of which is intended to reflect external needs, internal needs, the difference between the external and internal needs, uncertainty, etc. In Korea, the reliability and validity of this test were verified in a study conducted on 230 patients in $1996 .^{27}$

\section{Statistical analyses}

A paired t-test was performed to examine the changes in the mean scores on the IES-R-K and BEPSI-K before and after training. In addition, Pearson's correlation was used to determine the correlation between the IES-R-K and BEPSI-K scores and between the K-WURS and IES-R-K scores before and after training. To analyze PTSD onset (IES-R-K $\geq 18$ ) risk factors before and after training, a multivariate logistic regression analysis, which included K-WURS, K-AADHDS, and demographical variables, was conducted. Also, path analysis was performed to estimate the causal relationship between the past and present ADHD symptoms and the PTSD symptoms before and after training. The SPSS version 12.0 (SPSS Inc., Chicago, IL, USA) and AMOS 18.0 (SPSS Inc., Chicago, IL, USA) statistics software packages were used for all statistical analyses. Statistical significance for all analyses was defined as $\mathrm{p}<0.05$.

\section{RESULTS}

Two hundred and fifty-eight participants answered the first survey, and 271 participants answered the second survey. Only the 224 participants who answered both the first and second surveys were included as study subjects. The first survey was conducted on the first day after admittance, and the second survey was conducted after the 5 weeks of basic military training.

The demographic variables are shown in Table 1 . The mean age of the 224 new recruits participating in the study was $19.8 \pm 1.1$, and college enrollment (92.4\%) was the most common education level. The results revealed that $1.3 \%$ had a personal medical history of psychiatric disorder, and $2.7 \%$ had a family medical history of psychiatric disorder. The changes in the stress scale and IES-R-K scores before and after the training are shown in Table 2. A significant decrease in the stress scale was observed after the 5-week long training. The BEPSI-K score was $1.51 \pm 0.4$ before training and $1.26 \pm 0.5$ after the 5 -week training $(\mathrm{p}<0.01)$. The PTSD symptoms represented by the IES-R-K score also displayed a significant de-

Table 1. Demographic characteristics of 224 subjects enrolled in Korean conscripts

\begin{tabular}{lc}
\hline \multicolumn{1}{c}{ Variables } & $\mathrm{N}=224$ \\
\hline Age (years, mean $\pm \mathrm{SD})$ & $19.8 \pm 1.1$ \\
Education & \\
High school (N, \%) & $12(5.4)$ \\
University student & $207(92.4)$ \\
College graduate & $2(0.9)$ \\
University graduate & $3(1.3)$ \\
Psychiatric history (N, \%) & \\
Yes & $3(1.3)$ \\
No & $221(98.7)$ \\
Psychiatric family history (N, \%) & \\
Yes & $6(2.7)$ \\
No & $218(97.3)$ \\
Parents (N, \%) & \\
Both parents & $200(89.3)$ \\
Single parent & $23(10.3)$ \\
Parent in law & $0(0)$ \\
Without parents & $1(0.4)$ \\
Economic status (10000 won) & \\
Below 99 & $7(3.1)$ \\
100-199 & $37(16.5)$ \\
300-299 399 & $47(21.0)$ \\
Above 400 & $48(21.4)$ \\
\hline
\end{tabular}


Table 2. Comparison of IES-R-K, BEPSI-K scores before and after basic military training

\begin{tabular}{llrc}
\hline & First week & Last week & $\mathrm{p}$ \\
\hline IES-R-K (SD) & $10.2(11.7)$ & $3.8(5.5)$ & 0.001 \\
BEPSI-K (SD) & $1.51(0.4)$ & $1.26(0.5)$ & 0.001 \\
\hline
\end{tabular}

IES-R-K: Impact of Event Scale-Revised Korean version, BEPSI-K: Brief Encounter PsychoSocial Instrument-K, SD: standard deviation

Table 3. The correlation among score of IES-R-K, BEPSI-K and adult ADHD symptoms during basic military training

\begin{tabular}{lcc}
\hline & K-WURS-25 & K-AADHDS \\
\hline 1st week IES-R-K & $0.575^{* *}$ & $0.642^{* *}$ \\
Last week IES-R-K & $0.213^{* *}$ & $0.172^{* *}$ \\
1st week BEPSI-K & $0.606^{* *}$ & $0.524^{* *}$ \\
Last week BEPSI-K & $0.248^{* *}$ & $0.161^{*}$ \\
\hline
\end{tabular}

${ }^{*} \mathrm{p}<0.05,{ }^{* *} \mathrm{p}<0.01$. IES-R-K: Impact of Event Scale-Revised Korean version, BEPSI-K: Brief Encounter PsychoSocial Instrument-K, K-AADHDS: Korean Adult Attention Deficit Hyperactivity Disorder Scale, K-WURS-25: Korean-Wender Utha Rating Scale-25

Table 4. Predictors of suspicious PTSD(IES-R-K>17) in $1^{\text {st }}$ week during basic military training by multivariate logistic regression analysis

\begin{tabular}{ccccc}
\hline & $\mathrm{B}$ & $\beta$ & Sig. & OR $(95 \% \mathrm{CI})$ \\
\hline K-AADHDS & 0.136 & 0.042 & 0.001 & $1.145(1.054-1.245)$ \\
K-WURS-25 & 0.048 & 0.022 & 0.028 & $1.049(1.005-1.095)$ \\
\hline
\end{tabular}

B: unstandardized regression coefficient, $\beta$ : standardized regression coefficient, Sig.: significance probability, OR: odds ratio, CI: confidence interval. PTSD: post traumatic stress disorder, IES-RK: Impact of Event Scale-Revised Korean version, K-AADHDS: Korean Adult Attention Deficit Hyperactivity Disorder Scale, KWURS-25: Korean-Wender Utha Rating Scale-25

crease after training $(\mathrm{p}<0.01)$; the test yielded a score of $10.2 \pm$ 11.7 before training and $3.8 \pm 5.5$ after the five-week training. The group presenting questionable PTSD (IES-R-K score over 18 points) consisted of 44 subjects (19.6\%) before training and 4 subjects (1.8\%) after training.

The correlations among the presence and absence of the ADHD symptoms in the past and in the present, the IES-R-K score, and the BEPSI-K score were analyzed (Table 3). Before training, the coefficients of correlation between the IES-R-K score and the K-WURS score and between the IES-R-K score and the K-AADHDS score were 0.575 and 0.642 , respectively, which indicates significant correlation $(\mathrm{p}<0.01)$. After five weeks of training, the coefficients of correlation between the IES-R-K score and the K-WURS score and between the IES$\mathrm{R}-\mathrm{K}$ score and the K-AADHDS score were 0.213 and 0.172 , respectively, which indicates significant correlation $(\mathrm{p}<0.01)$. In the first week of training, the coefficients of correlation between the BEPSI-K score and the K-WURS score and between the BEPSI-K score and the K-AADHDS score were 0.606 and
Table 5. Predictor of suspicious PTSD(IES-R-K>17) in last week during basic military training by multivariate logistic regression analysis

\begin{tabular}{ccccc}
\hline & B & $\beta$ & Sig. & OR (95\% CI) \\
\hline 1st week IES-R-K & 0.071 & 0.026 & 0.006 & $1.073(1.020-1.129)$ \\
\hline
\end{tabular}

B: unstandardized regression coefficient, $\beta$ : standardized regression coefficient, Sig.: significance probability, OR: odds ratio, CI: confidence interval. PTSD: post traumatic stress disorder, IES-R-K: Impact of Event Scale-Revised Korean version

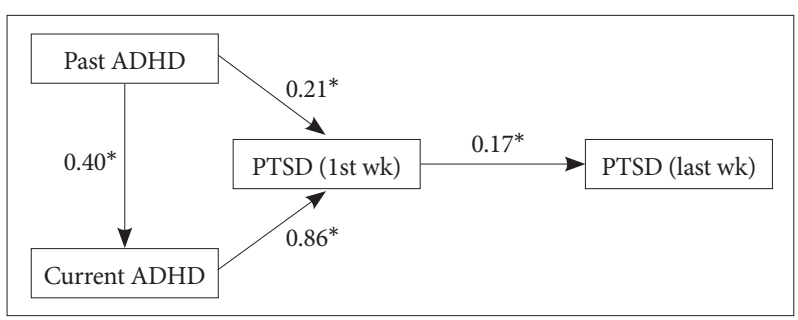

Figure 1. Path analysis of effect of adult ADHD on PTSD. ${ }^{*} p<0.05$. PTSD: post trauma stress disorder, ADHD: attention deficit hyperactivity disorder.

0.524 , respectively, indicating significant correlation $(\mathrm{p}<0.01)$. After the five-week training, the coefficients of correlation between the BEPSI-K score and the K-WURS score and between the BEPSI-K score and the K-AADHDS score were 0.248 and 0.161 , respectively, which indicates significant correlation $(\mathrm{p}<0.05$ and $\mathrm{p}<0.01$, respectively). The PTSD risk factors before and after training are shown in Table 4. In the first week of training, all of the past and present ADHD symptoms were risk factors for the PTSD questionable group (IES-R-K $\geq 18$ ). The risk of PTSD in the group that exhibited present ADHD symptoms was 1.145 times higher. The risk of PTSD in the group that showed past ADHD symptoms was 1.049 times higher than in the group without past ADHD symptoms. The risk of PTSD in last week was 1.073 times higher in the group with PTSD symptoms in first week than in the group without PTSD symptoms in first week (Table 5). Path analyses of the past and present ADHD symptoms and the PTSD symptoms before and after training were conducted to examine any causal relationships (Figure 1). The model was validated with a chi-squared of 8.934 and a significance level of $\mathrm{p}=0.112$. The GFI was 0.985 , which exceeds 0.9 and thus indicates high validity, and an AGDF of 0.956 also confirmed the validity of the model. Other indexes of model validation were as follows: RMSEA $=0.059$, RMR $=0.709$, and $\mathrm{CFI}=0.988$.

Regarding the effects of the exogenous variables on the endogenous variables found in the path analysis, the path coefficient from the K-WURS score, which represented past ADHD symptoms, to the K-AADHDS score, which represented present ADHD symptoms, was 0.40 (S.E: 0.024, C.R: 16.918), and that to the first week IES-R-K score, which represented the PTSD symptoms before training, was 0.21 (S.E: 
0.073, C.R: 2.878); both coefficients indicate direct effects. Regarding the path coefficients between the endogenous variables, the path coefficient from the K-AADHDS score to the first week IES-R-K score, was 0.86 (S.E: 0.137, C.R: 6.26), indicating direct effects. The path coefficient from the first week IES-R-K score to the last week IES-R-K score, which represented the PTSD symptoms after training, was 0.17 (S.E: 0.03, C.R: 5.672), indicating direct effects. All of the abovementioned path coefficients were significant at the $5 \%$ level.

\section{DISCUSSION}

This study was a 5-week long prospective study conducted to investigate the effects of ADHD symptoms on PTSD symptoms using new recruits participating in basic military training as the study subjects. The group with past and present adult ADHD symptoms had a higher risk of developing PTSD symptoms than the group without symptoms. In addition, a causal relationship between ADHD symptoms and PTSD symptoms was found. The IES-R-K and BEPSI-K scores decreased significantly after training. This result is similar to those of past studies that also used new recruits as the subjects. It seems that improved understanding about and adjustment to military life as well as the establishment of new relationships in a community setting led to psychological stability as the training progressed. ${ }^{27}$ Also, the relief of safely completing the challenging physical training likely reduced depression and anxiety. ${ }^{28,29}$

The new recruits who had experienced ADHD symptoms during childhood or the preceding 6 months had a higher risk of exhibiting PTSD symptoms before the training. The new recruits who had experienced PTSD symptoms before the training were also more likely to exhibit PTSD symptoms after the training. These results indicate that past and present ADHD symptoms are risk factors for PTSD symptoms, which is similar to the results of past studies., ${ }^{2,12}$ One study reported that PTSD patients had activity levels as high as those of ADHD patients when compared with the normal control group; that study concluded that comorbidity of these two diseases is possible and differential diagnosis is important. ${ }^{30}$ Another study comparing a panic disorder patient group and a PTSD patient group showed that the PTSD group exhibited more past and present ADHD symptoms than the panic disorder group and reported that ADHD is a PTSD vulnerability factor. ${ }^{2}$ Yet another study reported that, when exposed to traumatic stress, ADHD patients and ODD patients exhibited stronger PTSD symptoms than adjustment disorder patients. ${ }^{12}$ These results, like those of this current study, suggest that ADHD symptoms can heighten the risk of PTSD.

However, a study that comparatively analyzed an ADHD patient group and a normal control group reported that, although the risk of developing PTSD after exposure to trauma is not related to ADHD, mania is a risk factor for PTSD. ${ }^{31}$ The symptoms of ADHD and mania are difficult to differentiate, and it is easy to overlook the ADHD symptoms when both are present. ${ }^{32}$ Because this study completely precluded those subjects who were found to have major psychiatric disorders like mania in the post-conscription physical examination, it was impossible to compare mania and ADHD in this study.

A deficiency in executive function is characteristic ${ }^{33}$ of adults exhibiting ADHD. A study conducted on Vietnam War veterans found that low executive function was a risk factor for PTSD. ${ }^{34}$ A PTSD study conducted in Korea on the survivors of gun murder cases in the military also reported that executive function deficiency was a risk factor for PTSD. ${ }^{35} \mathrm{~A}$ twin study also indicated that executive function deficiency was a risk factor of PTSD. ${ }^{36}$ Considering the numerous past studies that suggest executive function deficiency is present in ADHD and PTSD, the deduction that ADHD and PTSD are closely related to executive function deficiency was made from the path analysis results of this study.

This study has several limitations. First, the evaluating instruments used in this study were not able to diagnose ADHD or PTSD. Subjects were included in the study when ADHD or PTSD was questionable or when symptoms were present, which cannot be taken as clear diagnoses. Second, a differential diagnosis is needed because ADHD and PTSD share many symptoms. ${ }^{37}$ For example, symptoms such as attention difficulties, fidgeting, impulsiveness, annoyance, and others may simultaneously exist in these two disorders. ${ }^{38}$ This study did not attempt to differentiate these two disorders, which might have affected the results. Therefore, a study in which a diagnosis and a differential diagnosis are made by a proficient interviewer is needed. Third, several studies assert that ADHD has many comorbidities. ${ }^{11,39-41}$ The comorbidities influence $\mathrm{ADHD}$ in a number of ways when present, but this study was not able to exclude these comorbidities. However, the new recruits were examined to confirm the absence of major diseases in the mental and physical health examinations before they entered military service. For this reason, it was considered unlikely that the new recruits had comorbidities.

Despite these limitations, this prospective study of adult ADHD symptoms and PTSD symptoms is significant. Furthermore, because the study subjects belonged to the same community, confounding factors such as type of trauma, degree of exposure, sex, age, etc. were relatively controlled. By examining ADHD symptoms in soldiers and observing the progress of PTSD symptoms, this study is expected to aid in the evaluation and understanding of the social issues underlying soldier adjustment. Based on the results of this study re- 
garding the relationship of symptoms between PTSD and ADHD, it will be possible to study the biological etiology shared by ADHD and PTSD.

\section{REFERENCES}

1. Stallard P, Salter E, Velleman R. Posttraumatic stress disorder following road traffic accidents - a second prospective study. Eur Child Adolesc Psychiatry 2004;13:172-178.

2. Adler LA, Kunz M, Chua HC, Rotrosen J, Resnick SG. Attention-deficit/hyperactivity disorder in adult patients with posttraumatic stress disorder (PTSD): is ADHD a vulnerability factor? J Atten Disord 2004; 8:11-16.

3. Sadock BJ, Sadock VA, Jack AG, Caroly SP, Norman S. Posttraumatic Stress Disorder and Acute Stress Disorder: Etiology. In: Sadock BJ, Sadock VA, Editors. Kaplan and Sadock's Synopsis of Psychiatry: Behavioral Sciences/Clinical Psychiatry, 10th Edition. Philadelphia: Lippincott Williams and Wilkins, 2007, p. 613.

4. Kessler RC, Sonnega A, Bromet E, Hughes M, Nelson CB. Posttraumatic stress disorder in the National Comorbidity Survey. Arch Gen Psychiatry 1995;52:1048-1060.

5. Cantwell DP. Attention deficit disorder: a review of the past 10 years. J Am Acad Child Adolesc Psychiatry 1996;35:978-987.

6. McIntosh D, Kutcher S, Binder C, Levitt A, Fallu A, Rosenbluth M. Adult ADHD and comorbid depression: A consensus-derived diagnostic algorithm for ADHD. Neuropsychiatr Dis Treat 2009;5:137-150.

7. Faraone SV, Biederman J, Mick E. The age-dependent decline of attention deficit hyperactivity disorder: a meta-analysis of follow-up studies. Psychol Med 2006;36:159-165.

8. Barkley RA, Fischer M, Smallish L, Fletcher K. The persistence of attention-deficit/hyperactivity disorder into young adulthood as a function of reporting source and definition of disorder. J Abnorm Psychol 2002; 111:279-289.

9. Borland BL, Heckman HK. Hyperactive boys and their brothers. A 25year follow-up study. Arch Gen Psychiatry 1976;33:669-675.

10. Biederman J, Faraone SV, Spencer T, Wilens T, Mick E, Lapey KA. Gender differences in a sample of adults with attention deficit hyperactivity disorder. Psychiatry Res 1994;53:13-29.

11. Kessler RC, Adler L, Barkley R, Biederman J, Conners CK, Demler O, et al. The prevalence and correlates of adult ADHD in the United States: results from the National Comorbidity Survey Replication. Am J Psychiatry 2006;163:716-723.

12. Ford JD, Racusin R, Ellis CG, Daviss WB, Reiser J, Fleischer A, et al. Child maltreatment, other trauma exposure, and posttraumatic symptomatology among children with oppositional defiant and attention deficit hyperactivity disorders. Child Maltreat 2000;5:205-217.

13. Weinstein D, Staffelbach D, Biaggio M. Attention-deficit hyperactivity disorder and posttraumatic stress disorder: differential diagnosis in childhood sexual abuse. Clin Psychol Rev 2000;20:359-378.

14. Barkley RA, Brown TE. Unrecognized attention-deficit/hyperactivity disorder in adults presenting with other psychiatric disorders. CNS Spectr 2008; 13:977-984.

15. Shin H. The Effects of College Student's Self-Efficacy on the Ways of Coping Stress and Social Problem-Solving Ability. Seoul: Kwangwoon University; 2006.

16. Shin MO. An Analytical Study of Psychological Anxiety of Replacement Training Center Recruit. Seoul: The Graduate School of Education, Ewha Woman University; 1999.

17. Lee JH, Cho JY. Anxiety, depression and impulsiveness according to military service duration in army-enlisted males. J Korean Neuropsychiatr Assoc 1999;38:966-972.

18. Jung ES. The effect of psychological hardiness on mental health in the new military recruits basic training period- mediated by ways of coping and achievement goals. Korean J Couns Psychotherapy 2007;19:191-
211.

19. Mikulincer M, Florian V, Weller A. Attachment styles, coping strategies, and posttraumatic psychological distress: the impact of the Gulf War in Israel. J Pers Soc Psychol 1993;64:817-826.

20. Norvilitis JM, Sun L, Zhang J. ADHD symptomatology and adjustment to college in China and the United States. J Learn Disabil 2010;43:8694.

21. Kim EJ. The validation of Korean Adult ADHD scale. Korean J Clin Psychol 2003;22:897-911.

22. Lee KS, Ahn JS, Shin JH. Attention-deficit hyperactivity symptoms in childhood of adult bipolar disorder/schizophrenia patients. Korean J Child Adoles Psychiatry 1998;9:26-33.

23. Horowitz M, Wilner N, Alvarez W. Impact of Event Scale: a measure of subjective stress. Psychosom Med 1979;41:209-218.

24. Joseph S. Psychometric evaluation of Horowitz's Impact of Event Scale: a review. J Trauma Stress 2000;13:101-113.

25. Weiss DS, Marmar CR. The Impact of Event Scale-Revised. In: Wilson JP, Keane TM, Editors. Assessing Psychological Trauma and PTSD. New York: Guilford Press, 1997, p.399-411.

26. Eun HJ, Kwon TW, Lee SM, Kim TH, Choi MR, Cho SJ. A study on reliability and validity of the Korean version of Impact of Event Scale-Revised. J Korean Neuropsychiatr Assoc 2005;44:303-310.

27. Yim JH, Bae JM, Choi SS, Kim SW, Hwang HS, Huh BY. The validity of modified Korean translated BEPSI as instrument of stress measurement in outpatient clinic. J Korean Acad Fam Med 1996;17:42-53.

28. Koo JS, Choi TY, Lee JH. Depression, anxiety and suicidal ideation according to basic military training duration in Air Force conscipts. Anxiety Mood 2009;5:89-95.

29. Martin PD, Williamson DA, Alfonso AJ, Ryan DH. Psychological adjustment during Army basic training. Mil Med 2006;171:157-160.

30. Glod CA, Teicher MH. Relationship between early abuse, posttraumatic stress disorder, and activity levels in prepubertal children. J Am Acad Child Adolesc Psychiatry 1996;35:1384-1393.

31. Wozniak J, Crawford MH, Biederman J, Faraone SV, Spencer TJ, Taylor A, et al. Antecedents and complications of trauma in boys with ADHD: findings from a longitudinal study. J Am Acad Child Adolesc Psychiatry 1999;38:48-55.

32. Sood AB, Razdan A, Weller EB, Weller RA. How to differentiate bipolar disorder from attention deficit hyperactivity disorder and other common psychiatric disorders: a guide for clinicians. Curr Psychiatry Rep 2005;7:98-103.

33. Kessler RC, Green JG, Adler LA, Barkley RA, Chatterji S, Faraone SV, et al. Structure and diagnosis of adult attention-deficit/hyperactivity disorder: analysis of expanded symptom criteria from the Adult ADHD Clinical Diagnostic Scale. Arch Gen Psychiatry 2010;67:1168-1178.

34. Gale CR, Deary IJ, Boyle SH, Barefoot J, Mortensen LH, Batty GD. Cognitive ability in early adulthood and risk of 5 specific psychiatric disorders in middle age: the Vietnam experience study. Arch Gen Psychiatry 2008;65:1410-1418.

35. Kim TY, Chung HG, Choi JH, Shin HS, Song DH, Chung MY, et al. Cognitive Deficits Associated with Posttraumatic Stress Disorder. J Korean Neuropsychiatr Assoc 2009;48:12-20.

36. Gilbertson MW, Paulus LA, Williston SK, Gurvits TV, Lasko NB, Pitman RK, et al. Neurocognitive function in monozygotic twins discordant for combat exposure: relationship to posttraumatic stress disorder. J Abnorm Psychol 2006;115:484-495.

37. McLeer SV, Callaghan M, Henry D, Wallen J. Psychiatric disorders in sexually abused children. J Am Acad Child Adolesc Psychiatry 1994;33: 313-319.

38. Blank AS Jr. Clinical detection, diagnosis, and differential diagnosis of post-traumatic stress disorder. Psychiatr Clin North Am 1994;17:351383.

39. Pliszka SR. Comorbidity of attention-deficit/hyperactivity disorder with psychiatric disorder: an overview. J Clin Psychiatry 1998;59(Suppl 7): 50-58. 
40. Milberger S, Biederman J, Faraone SV, Murphy J, Tsuang MT. Attention deficit hyperactivity disorder and comorbid disorders: issues of overlapping symptoms. Am J Psychiatry 1995;152:1793-1799.
41. Fayyad J, De Graaf R, Kessler R, Alonso J, Angermeyer M, Demyttenaere $\mathrm{K}$, et al. Cross-national prevalence and correlates of adult attention-deficit hyperactivity disorder. Br J Psychiatry 2007;190:402-409. 